\title{
X. On the "Dimensions" of temperature in length, mass, and time; and on an absolute C.G.S. unit of temperature
}

\section{Charles V. Burton B.Sc.}

To cite this article: Charles V. Burton B.Sc. (1887) X. On the "Dimensions" of temperature in length, mass, and time; and on an absolute C.G.S. unit of temperature, Philosophical Magazine Series 5, 24:146, 96-98, DOI: 10.1080/14786448708628064

To link to this article: http://dx.doi.org/10.1080/14786448708628064

曲 Published online: 29 Apr 2009.

Submit your article to this journal $[\pi$

Џll Article views: 5

Q View related articles $\llbracket$ 
A more suitable core for the helix than indiarubber is the flexible gas-tubing made of plaited and varnished canvas. It is very uniform in cross section; and by withdrawing the metal spiral upon which it is woven and mounting it on a spindle in a screw-cutting lathe, it is easy to wind the wire uniformly upon it.

The use of the lathe is the more desirable, as measurements of potential by the helix depend very much for their accuracy upon the uniformity with which it is wound ; this being especially the case if its position in the field does not happen to coincide with the direction of the lines of force.

To keep the turns in place the small spaces between them may be filled with soft cotton-thread.

University College, Bristol.

X. On the "Dimensions" of Temperature in Length, Mass, and Time; and on an Absolute C.G.S. Unit of Temperature. By Charles V. Burton, B.Sc. (Lond.).*

GIR W. THOMSON'S second absolute scale gives us the $D$ means of finding the ratio between two temperatures, independently of any arbitrary convention as to the size of degrees. We are therefore bound to consider temperature as a physical quantity capable of exact measurement. Now every such quantity has certain dimensions in length, mass, and time; and $I$ here propose to find the dimensions of temperature.

Let temperatures be represented on Sir W. Thomson's absolute scale, so that nothing remains arbitrary except the size of the degrees. Consider an absolutely perfect gas whose temperature on this scale $=t$. Let the mean kinetic energy of a molecule of the gas $=\mathrm{E}$. Then we have

$$
\mathrm{E}=k t, \text {. . . . . . }
$$

where $k$ is the same for all temperatures and for all perfect gases; being independent of the mass per molecule of the gas, and determined solely by the size of the degrees on our scale of temperature.

If we write (1) in the form

$$
t=\frac{\mathrm{E}}{k}, \cdot \cdot \cdot \cdot \cdot \cdot \cdot .
$$

we see that a temperature $(t)$ is completely determined by the average-kinetic-energy-per-molecule $(\mathrm{E})$ of a perfect gas

* Communicated by the Author. 
which has that temperature; and that $t$ is proportional to E. Thus temperature is a quantity of the same kind as energy, and its dimensions are therefore

\section{$\mathrm{ML}^{2} \mathrm{~T}^{-2}$.}

Again, we have seen that $k$ depends only on the size of the degrees on our scale of temperature; and these degrees have hitherto been chosen of an arbitrary size.

If we were intimately acquainted with the constitution of bodies, the mass of their separate molecules, and so on, we should be able (without requiring any experiments on that hypothetical condition of matter called "perfect gas ") to find the value of $k$ corresponding to degrees of any given size on the absolnte scale. Or, again, a given value of $k$ will determine the size of the degrees on our scale. If we assume $k=1$, we get an absolute unit of temperature, derived from those of length, mass, and time, and independent of any other quantities. The relation (2) then becomes $t=\mathrm{E} ; i$. e. any temperature is measured by the mean-kinetic-energy-per-nolecule of a perfect gas having that temperature. With the C.G.S. system of units, the unit temperature would be that of a perfect gas whose mean kinetic eneroy per molecule was one erg.

From our present knowledge of the mass of molecules, and of the properties of imperfect gases, we may form a very rough idea of the relation between the Centigrade and the C.G.S. scales of temperature. For a perfect gas we have the relation

$$
\begin{aligned}
\mathrm{PV} & =\frac{2}{3} \times \text { kinetic energy of gas, } \\
& =\frac{2}{3} n \mathrm{E} ;
\end{aligned}
$$

where $n=$ number of molecules in the volume $\mathrm{V}$, and $\mathrm{E}$, as before, is the mean-kinetic-erergy-per-molecule. Now let $\mathrm{P}=$ one atmosphere $=($ roughly $)$ i $0^{6}$ dynes per square centimetre, let $V=1$ cubic centim., and let the temperature be $0^{\circ} \mathrm{C}$. Then, according to Sir W. Thomson's metsurements, $n=$ about $6 \times 10^{21}$;

$$
\begin{aligned}
\therefore \mathrm{E} & =\frac{3}{2} \cdot \frac{\mathrm{PV}}{n}, \\
& =\frac{3}{2} \cdot \frac{10^{6} \times 1}{6 \times 10^{21}}, \\
& =2 \cdot 5 \times 10^{-16} .
\end{aligned}
$$

This number is then a very rough estimation of the value of the temperature $0^{\circ} \mathrm{C}$. in absolute C.G.S. measure. Thus 273 Centigrade degrees are equivalent to $2.5 \times 10^{-16}$ absolute Phil. Mug. S. 5. Vol. 24. No. 146. July 1887. 
units of temperature; therefore the absolute unit of temperature is equivalent to

$$
\begin{aligned}
& \frac{273}{2 \cdot 5} \times 10^{16} \text { Centigrade degrees, } \\
& =\text { about } 10^{18} \text { Centigrade degrees. }
\end{aligned}
$$

These figures are only intended to convey a very rough notion of the relation. They cannot of course be considered as even approximately correct, owing to the great uncertainty as to the mass of molecules.

Having seen that temperature is a quantity of the same dimensions as energy, and knowing that the same is also true of heat, it follows that entropy, whose dimensions are heat $\div$ temperature, is a purel $r$ numerical quantity ; and the unit of entropy is therefore independent of all other physical units. In fact, the entropy of a perfect gas increases by unity, when (without altering in temperature) it receives by conduction a quantity of heat equal to the mean energy of one of its molecules. This is seen by putting

$$
\frac{\Delta \mathrm{H}}{\Theta}=1 ; \therefore \Delta \mathrm{H}=\Theta=\mathrm{E},
$$

where $\Theta$ is the absolute (C.G.S.) temperature.

\section{Researches on Spectrum Analysis. By Prof. A. F. Sundelit*.}

CERTAIN natural phenomena, such as the aurora borealis, zodiacal light, and solar corona, have occasioned numerous attempts to obtain the spectra of gases in a highly rarefied condition and at a low temperature. Under these conditions spectra generally become very feeble, and therefore difficult to observe. The following experiments show that tolerably bright spectra may be obtained by an advantageous employment of means already known.

Since the brightness of the spectrum depends, in the first place, upon the thickness of the radiating layer, "end-on" tubes $\dagger$ are employed by preference. I have employed tubes as long as possible (up to $1 \frac{1}{2}$ metre long). The end towards the spectroscope was simply melted together, and rounded as well as might be in the process. The other end was drawn out and melted on to the tubes leading to the mercury-pump.

* Translated from a separate impression from the Acta Societatis Scientiarum Fennice, vol. xv., communicated by the Author.

† Such tubes have been employed by Prof. P. Smyth for observations un gaseous spectra in vacuo (Beibl. vii. 1883, p. 286). 